\title{
Auge e declínio do "neodesarrollismo" argentino *
}

\author{
Iderley Colombini Neto **
}

\begin{abstract}
Resumo
O presente artigo busca analisar o neodesenvolvimentismo argentino a partir dos seus eixos constituintes e de como eles se modificaram ao longo dessa última década. O novo desenvolvimentismo argentino entendido aqui não é visto como uma atitude isolada do 'kirchnerismo' e das políticas governamentais, mas como um processo da junção do ambiente interno argentino com a nova reestruturação do sistema capitalista pós-crise neoliberal.
\end{abstract}

Palavras-chave: Argentina; Desenvolvimento econômico; Novo-Desenvolvimentismo; América Latina; Lutas de classe.

\section{Abstract \\ The peak and decline of neo-developmentalism in Argentina}

The aim of this paper is to analyze neo-developmentalism in Argentina based on its constituents' axes and how they changed over the last decade. New developmentalism in Argentina as understood here is not seen as an isolated attitude of 'kirchnerism' and of government policies, but as a process of joining the Argentine internal environment with the new structure of the capitalist system after the neoliberal crisis.

Keywords: Argentina; Economic development; Neo-development; Latin America; Class struggle. JEL O540, O100, F590, N460.

\section{Introdução}

No começo desse novo milênio, grandes mudanças estruturais ocorreram na economia mundial. Em meados dos anos 90, o modelo neoliberal parecia indiscutível, apesar das intensas manifestações sociais, no plano econômico a aparente estabilidade era vista com extrema euforia na América Latina. Entretanto, depois das décadas de 80 e 90 marcadas pelo neoliberalismo, um período de crises financeiras consecutivas marcou o final da década de 90 nos países periféricos ${ }^{1}$. Atualmente se torna possível ver como essas crises podem ser consideradas um marco para um novo modelo político-econômico nos países latinos, que apesar de conter continuidades, apresenta claramente novos padrões. A eleição de Hugo Chávez em 1998 já

* Artigo recebido em 25 de junho de 2014 e aprovado em 22 de janeiro de 2016.

** Doutorando em Economia pela Universidade Federal do Rio de Janeiro (IE/PPGE-UFRJ). O autor agradece ao financiamento da CAPES que possibilitou a realização desse trabalho e aos comentários de Daniela Araújo, André Augustin e Carlos Aguiar de Medeiros, obviamente não os comprometendo por eventuais equívocos e omissões existentes nesse trabalho, sendo de total responsabilidade do autor. E-mail: iderley_colombini@hotmail.com.

(1) Menção às crises financeiras na Rússia em 97, asiáticas em 98, brasileira em 99 e a argentina em 2001. 
assinalava uma nova tendência de uma nova corrente na América Latina, que irá se consolidar com o presidente Lula no Brasil em 2002 e finalmente com a eleição de Nestor Kirchner em 18 de maio de 2003.

As modificações nas lideranças dos países latinos também podem ser vistas pelas alterações econômicas. Assim, o ano 2.000 iniciou com um panorama diferente, marcado por um alto crescimento internacional, uma subida substantiva nos preços internacionais das commodities e um nível baixo de taxa de juros. Esses fatores advêm principalmente do crescimento da produção asiática, com um predomínio absoluto da China, que consolidou seu papel definitivo na economia mundial. Desta forma se criou espaço para um novo arranjo na produção internacional, surgindo oportunidades para vários países periféricos.

Os países latinos apresentaram uma situação particular em sua história econômica, com taxas constantes de crescimento e com equilíbrio na balança de pagamentos. Essa situação favorável foi acompanhada por um processo de fortalecimento do Estado, com uma ampliação das políticas tanto econômicas quanto sociais. Já nos primeiros anos da década começaram a surgir as primeiras análises evidenciando esse novo processo, dadas as recentes modificações em algumas políticas macroeconômicas que começavam a apresentar resultados positivos.

No caso Argentino essas análises podem ser representadas por Roberto Frenkel ${ }^{2}$ e pelo próprio "governo Kirchner" (Mechon, 2007). Em Mechon (2007) fica evidente a defesa de uma intenção do governo Kirchner em promover uma nova estratégia para um desenvolvimento da economia. Esse trabalho apresenta o estabelecimento de uma taxa de câmbio real competitiva, uma política físcal controlada e a implementação de políticas de renda com a intenção de melhorar a distribuição como as principais políticas do governo. Dessa forma defende que o governo busca, por meio de um conjunto de políticas macroeconômicas, gerar o crescimento com incentivos para o setor produtivo.

Frenkel defenderá o sucesso das políticas macroeconômicas do governo no período pós-convertibilidade, que contrariando as advertências do FMI promoveu uma política de câmbio real competitivo com crescimento econômico e inflação controlada. Segundo o autor, a forte desvalorização e a manutenção do câmbio em um patamar competitivo foi uma atitude acertada para promoção do crescimento e da estabilidade, o que permitiu também a promoção de novas políticas sociais e distribuição de renda ${ }^{3}$. Apesar da forte retração da economia e dos salários reais logo após a desvalorização, houve um forte crescimento e restabelecimento dos salários

(2) Nesse trabalho analisaremos os estudos: Frenkel e Rapetti (2011), Damill e Frenkel (2009) e Damill, Frenkel e Maurizio (2011)

(3) "The paper shows that domestic factors had the main bearing in explaining the 2002 turning point. The recovery was actually bolstered by the shift in the relative prices caused by the devaluation and also by an adequate set of policies that, despite some flaws and ambiguities, nevertheless succeeded in stabilizing the FX market and domestic prices and recuperating the basic macroeconomic equilibria" (Damill; Frenkel; Maurizio, 2011). 
e das taxas de lucros, o que seria provocado pela remodelação da economia ao novo nível de preços com um câmbio real mais competitivo.

Damill, Frenkel e Maurizio (2011) defendem a posição do presidente Kirchner e do seu então ministro da economia em promover simultaneamente uma política de câmbio competitivo com uma meta monetária quantitativa, o que contrariava o FMI baseado na ortodoxia econômica. Segundo os autores, o estabelecimento dessas políticas permitiu uma retomada do crescimento e do aumento do salário real ${ }^{4}$ graças à expansão da demanda agregada o que, acompanhado de políticas de renda específicas, levou também a uma redução da desigualdade. Desta forma os autores apresentam um quadro extremamente positivo das políticas implementadas pelo governo, que por meio de fatores domésticos guiavam corretamente a economia para o desenvolvimento.

Entretanto, como apresentaremos nesse trabalho, essas políticas implantadas apresentam atualmente grandes contradições em meio aos êxitos destacados. Primeiramente, deve ser contestada a própria importância da desvalorização na fase de "sucesso" do novo desenvolvimentismo. Não foram poucos economistas que depositaram todos os méritos do crescimento no começo desse século nas políticas cambiais, que possibilitariam por si só garantir uma balança de pagamentos superavitária e taxas crescentes de crescimento.

Nas economias com uma estrutura produtiva desequilibrada, as políticas cambiais não são suficientes para promover alteração estrutural via mudança nos preços relativos ${ }^{5}$. Apesar dos efeitos positivos iniciais dessas políticas, a própria manutenção da estrutura produtiva irá recolocar os mesmos conflitos anteriores, restabelecendo uma fase de desaceleração da economia.

Durante o período de pós-convertibilidade a desvalorização cambial foi necessária para se restabelecer as condições mínimas necessárias para retomada da economia, mas como mostraremos nas próximas seções, o grande mérito do crescimento e da maior distribuição econômica não foi essa política tão valiosa para os novos desenvolvimentistas, mas sim um conjunto de políticas fiscais e distributivas expansionistas. A importância do regime cambial na Argentina durante

(4) "Moreover, another important characteristic of the trajectory of wages has been the different evolution according to the educational level of workers. In particular, there has been a relative improvement in incomes of the less educated throughout this period: the real income of workers with incomplete secondary school or less increased 37 per cent as opposed to a 24 per cent rise for those with complete university. (...) One of these factors that have contributed to this process has been the significant incomes policy implemented by the National Government since mid-2002 thorough lump-sum rises and increments in the minimum wage" (Damil; Frenkel; Maurizio, 2007).

(5) Para uma análise mais aprofundada sobre as implicações da taxa de câmbio em economias com estrutura produtiva desiquilibrada ver: Diamand $(1973,1986)$. 
os anos 2000 possui um caráter secundário para explicar a trajetória econômica do país em relação às políticas expansivas utilizadas pelo governo.

Além da importância de descrever com mais cuidado as políticas implantadas e seus reais efeitos, deve-se considerar também a própria capacidade dessas políticas em gerar o tão sonhado desenvolvimento, ou se preferir, uma mudança estrutural e com o nível de renda dos países mais ricos.

Apesar das análises e críticas sobre o neodesenvolvimentismo explicarem a intenção dos governos nesse modelo político-econômico, elas possuem uma análise extremamente focada no papel do Estado em gerar o desenvolvimento e o tão sonhado crescimento com distribuição de renda. Desta forma, desconsideram os próprios limites colocados às políticas governamentais, que ditam não só as relações do país com outros países, mas também os conflitos de classe internos e como consequência os setores econômicos hegemônicos, os quais são condicionados pela própria estrutura produtiva do país. Logo, nesse trabalho se utiliza a noção de neodesenvolvimentismo, não como um conjunto (ou apenas uma) de políticas econômicas específicas, mas como um momento de avanço do capitalismo na América Latina iniciado por volta dos anos 2000.

Por isso julga-se fundamental, além do estudo das políticas macroeconômicas, a observação da formação do bloco histórico responsável pela possibilidade de implantação desse novo modelo e dessas novas políticas. A partir de uma perspectiva não reducionista, as implicações dos fatores externos e dos grupos internos se torna mais aparente, o que nos leva a reconsiderar essa primazia dos fatores domésticos como expostos pelos macroeconomistas desse novo desenvolvimento. Se as taxas de crescimento e a estabilidade se devem a determinadas políticas econômicas, o que se deve à existência dessas políticas, que no começo da década obtiveram uma das maiores taxas de crescimento econômico da América Latina e em 2012 umas das menores?

Em uma abordagem que não leve em excesso o 'nacionalismo metodológico"6 , se torna necessário uma dupla autonomia, uma referente ao Estado nacional com as classes sociais e outra desse Estado frente aos demais. Portanto, para analisar um modelo político-econômico, dois pontos principais se tornam fundamentais: i) não ignorar as diferenças de desafios e circunstâncias criadas pelas condições iniciais, as quais impõe circunstâncias e mecanismos diferentes para a economia e ii) levar em consideração que o ambiente externo não é o mesmo para todos os países em desenvolvimento, já que uma mesma fase do capitalismo possibilita diferentes inserções de acordo com a estrutura de cada país (Medeiros,

(6) Um tratamento mais aprofundado do 'nacionalismo metodológico' é realizado por Medeiros (2001; 2010). Esses trabalhos apresentam como as múltiplas relações do Estado irão caracterizar a trajetória econômica seguida pelos diferentes países. 
2010). Não há uma dissociação entre a esfera econômica e política na trajetória de desenvolvimento capitalista, não podendo, por tanto, deixá-las afastadas para a compreensão das economias capitalistas atuais. A função do pesquisador deve ser justamente se aprofundar nas relações políticas-econômicas para poder romper com as aparências dos efeitos das políticas macroeconômicas da atualidade.

Na próxima seção tentaremos levantar algumas discussões sobre os aspectos político-econômicos que sustentaram esse novo modelo, ou seja, nos atendo primeiramente nas divergências entre quais foram e quais deveriam ser as políticas capazes para dar forma a esse neodesenvolvimentismo. Assim, no final dessa primeira seção tentamos entender as diferenças entre o papel dos fatores externos, condensados na rejeição de um caso de doença holandesa para uma maior compreensão das condicionalidades dos fluxos de capitais internacionais e a fragilidade financeira decorrente.

$\mathrm{Na}$ seção seguinte tentaremos entender como se formou esse modelo político-econômico atual e quais são as principais diferenças e similaridades, em relação tanto ao neoliberalismo quanto ao nacional desenvolvimentismo. A comparação com os modelos anteriores nos possibilitará entender quais são as novas modificações e como elas estão interligadas com os grupos internos e com as relações do capitalismo internacional. Por fim, buscamos apontar alguns elementos que demonstram o acirramento e os limites desse modelo atual, como: a cisão social, o intenso conflito distributivo e a forte fuga de capitais com risco de crise cambial.

\section{Um novo modelo e suas políticas}

No começo desse novo milênio ocorreram grandes mudanças no sistema econômico mundial. As principais alterações podem ser destacadas por quatro traços principais: um aumento substancial do preço das commodities, baixa taxa de juros média, crescimento do comércio internacional e principalmente uma expansão contínua (altas taxas já na década de 80) da produção de mercadorias industriais na Ásia. A incorporação definitiva da China como uma das grandes potências industriais teve um grande destaque. Essas circunstâncias propiciaram um momento único para vários países periféricos, como foi o caso dos países latino-americanos, que puderam obter um raro crescimento econômico com equilíbrio na balança de pagamentos. Dado essa maior estabilidade econômica e relativa autonomia puderam realizar políticas com um viés mais 'desenvolvimentista' ao invés das políticas ortodoxas que marcaram o período neoliberal. Por isso essa última década tem sido caracterizada como neodesenvolvimentismo que, diferentemente de grande parte dos estudos macroeconômicos, não significa um conjunto de políticas, mas uma fase de 
expansão do capitalismo internacional nos países da América Latina que se iniciou por volta dos anos $2000^{7}$.

A política econômica argentina atual reúne muitos elementos que a caracterizam claramente dentro desse neodesenvolvimentismo. A fase política econômica atual da Argentina sucedeu um ambiente de completa devastação do seu sistema econômico. Nenhuma outra crise anterior teve implicações tão graves no que tange: ao confisco de depósitos bancários ( "corralito"), paralisação dos pagamentos da dívida (moratória), massificação do desemprego, explosão da pobreza e demolição da indústria nacional como foi observado durante a crise de 2001. A Argentina apresentava, em 1980, níveis de pobreza de $7 \%$ da população, de acordo com a Cepal, e de indigência de 2\%; enquanto no ano de 2002 estes níveis foram para $45 \%$ e $21 \%$ respectivamente.

Entretanto, o sistema econômico e social será reconstruído a partir de 2003 com o governo de Nestor Kirchner. Esse irá recompor a autoridade do Estado e promover a recuperação do país. Vale salientar o papel do então ministro da economia Lavagna (2002 a 2005) de não seguir as recomendações do FMI de implantação de medidas de estabilização, como políticas de aperto monetário e fiscal para contornar o risco inflacionário. A Argentina se encontrava em um momento de forte apelo social com paralisação da indústria, mas com um forte crescimento da agricultura devido ao aumento continuado do preço das commodities e um processo de remodelação do campo com grandes aportes de capitais estrangeiros. Assim, com uma grande capacidade ociosa da indústria e uma balança comercial extremamente confortável, foi possível realizar uma forte desvalorização e um conjunto de políticas fiscais expansionistas sem gerar grandes impactos inflacionários. Dessa maneira, conseguiu rapidamente restabelecer a economia argentina com a reconstrução do poder das classes dominantes e concedendo as melhorias sociais e democráticas para os grandes levantes da crise de 2001.

Logo em 2006 já foi possível observar grandes melhorias pelos indicadores econômicos e sociais. O crescimento do PIB desde 2003 tem apresentado taxas próximas de $8 \%$, com juros anuais entre 8\% e 11\% em 2006 (comparados aos próximos de $40 \%$ em 2003). O desemprego que atingia cerca de $30 \%$ dos trabalhadores logo antes da crise de 2001 passou para 10\% em 2006. Esta rápida melhora foi possível com o nítido fortalecimento do Estado e com um distanciamento dos principais pontos de sustentação do neoliberalismo. Assim o governo não deu continuidade ao processo de privatização, impôs maiores controles

(7) O modelo atual de desenvolvimento não ocorre somente pelas políticas macroeconômicas defendidas pelos novos desenvolvimentistas, nem apenas com as políticas caracterizadas como sociais, mas sim pela união dessas duas esferas. Por isso, utilizando o argumento de Armando Boito, denominamos esse período e esse modelo de Neo Desenvolvimentismo, como sendo "o desenvolvimentismo da época do capitalismo neoliberal" (Boito, 2012, p. 6). 
à abertura comercial com uma diminuição da desregulamentação do trabalho e o estabelecimento de políticas sociais e distributivas.

Entretanto esse vigor desenvolvimentista tem apresentado grandes desgastes nos últimos anos, tanto do ponto de vista econômico quanto social. O nível da inflação disparou nos últimos três anos. Enquanto o governo apresenta níveis de $10 \%$ ao ano (dados oficiais do $\operatorname{Indec}^{8}$ ), vários institutos de pesquisa, tanto privados quanto acadêmicos, mostram um patamar em torno dos $25 \%$. O crescimento econômico, um dos pilares do governo até então, fechou 2012 bem abaixo do esperado, evidenciando vários problemas estruturais e a desaceleração da demanda interna, mostrando a dificuldade de manter as políticas expansionistas e a coesão social obtida logo após a crise de 2001. A saída de capitais tem apresentado um ritmo crescente, o que já mostra a volta do velho dilema latino de fragilidade financeira, ao que o governo tem tentado combater ineficazmente com um controle sobre as divisas internacionais.

Apesar da continuação de uma grande entrada de capitais via exportação de bens primários durante os anos 2000, cada vez mais esse superávit tem sido colocado em questão. $\mathrm{O}$ ambiente atual argentino cada vez mais se assemelha com o velho momento de crise pré-desvalorização, em que muitas empresas e grandes grupos econômicos começam a recorrer ao dólar por meio do acesso privilegiado ao mercado externo, enquanto a grande maioria dos trabalhadores sofre com o processo de inflação e deterioração do salário real. Esse processo de fragilidade financeira, como descreveremos mais a frente, se apresenta como um problema estrutural, que juntamente com sua correlação com a estrutura distributiva possui elementos autônomos.

Essa nova fase da Argentina possui uma grande distinção em relação aos outros países identificados com o neodesenvolvimentismo. Enquanto o Brasil passou pela crise cambial de 1999 de forma relativamente tranquila, a crise do período de convertibilidade argentina foi extremamente severa, apresentando modificações tanto na estrutura produtiva quanto social. Durante a crise dos últimos anos da década de 90 houve uma saída em massa de capitais da Argentina e um aprofundamento do processo da oligarquia pampeana diversificada (com investimentos na indústria) de se concentrar no setor agropecuário, o que intensificou de maneira alarmante o processo de desindustrialização. Esse processo provocou uma desaceleração histórica da economia, o que fez eclodir um momento particular com relação aos movimentos sociais.

Os anos posteriores à mega desvalorização de 2002 obviamente apresentaram uma grande ligação com esse momento de crise da convertibilidade. Por isso não se pode considerar esse período como se a economia já estivesse funcionando em um padrão "normal”. Uma coisa é analisar o padrão de crescimento

(8) Indec - Instituto Nacional de Estadística y Censos. 
de uma indústria que está funcionando "normalmente" (em seu dia a dia), outra coisa é analisar o crescimento de uma indústria que estava parada e voltou a funcionar.

A falta de percepção desse peso da trajetória recente leva a grande parte das análises econômicas sobre a recuperação argentina a identificá-la como um momento de alcance supremo do desenvolvimento, em que se obteria um crescimento diversificado da indústria capaz de obter divisas e distribuição de renda. Curia (2008), muito próximo da análise de Damill, Frenkel e Maurizio (2011), entende o período de recuperação argentina como "Propia del desarrollo productivo integral, con predicamento industrial y sustentable en divisas” (Curia, 2008)9.

Ao invés de entender o período de recuperação como uma retomada mínima das taxas de lucro da economia juntamente com um impacto das novas políticas fiscais expansionistas, Curia (2008) identifica o período como um processo de desenvolvimento integral da economia, o qual seria capitaneado pela política de câmbio real desvalorizado. Frenkel e Rapetti (2011) também sustentam de forma contundente a importância das políticas de câmbio real competitivo, que seriam as responsáveis pelas altas taxas de crescimento da economia e para o fortalecimento da indústria argentina, o que daria viabilidade para políticas sociais e distributivas que poderiam levar a uma situação de desenvolvimento.

Essas afirmações possuem duas mistificações quanto ao desenvolvimento da economia argentina. A primeira referente a própria descrição do novo desenvolvimentismo argentino, cometendo equívocos na caracterização de quais foram os canais (políticas macroeconômicas) responsáveis pela formação desse período caracterizado como neodesenvolvimento. A segunda, que perpassa um número muito maior de economistas, refere-se ao próprio entendimento de como ocorre o desenvolvimento econômico no sistema capitalista, sendo centrado estritamente na intervenção econômica do Estado.

Independente de quais foram exatamente as políticas implementadas é inegável o traço comum desse momento: maior crescimento, políticas sociais, superávit e fortalecimento do setor exportador de commodities. No campo macroeconômico é necessário haver uma ponderação de quais foram as reais políticas implantadas e como elas evoluíram durante essa década. Se algum fator é apontado erroneamente como importante para esse momento, deve-se entender quais são os fatores relevantes, mas não apagar do campo de discussão a singularidade dessa fase devida a existência de uma ou outra política específica.

No caso da Argentina, o novo desenvolvimentismo, como mostram os trabalhos de Curia e Frenkel, foi muito associado aos impactos do câmbio

(9) "Se asocia con una movilización integral de los recursos productivos de la nación, apuntando a un ascendente predicamento industrial, de manera de alcanzar peldaños superiores en materia de diversificación productiva, de valor agregado y de incorporación de tecnología” (Curia, 2008). 
desvalorizado, que ao mesmo tempo produziria um superávit comercial com um aquecimento da indústria. Essa afirmação possui um erro duplo, tanto por esse crescimento não ter como principal causa as políticas cambiais, quanto por esse momento histórico não se resumir apenas a políticas macroeconômicas.

Como mostrou Amico (2013), o crescimento na Argentina após a crise de convertibilidade está muito mais ligado a um conjunto de políticas fiscais e sociais, que levaram a um crescimento da demanda efetiva, do que à uma política de câmbio desvalorizado ${ }^{10}$. Um dos fatores decisivos desse crescimento argentino foi o vigoroso crescimento do consumo privado, que cresceu à taxa média anual de $7,75 \%$ entre 2003-2011. Esse forte crescimento pode ser vinculado a dois fatores principais: o forte aumento de crédito para consumo e ao aumento da renda.

O aumento da renda se deu em grande parte pelo aumento dos salários reais e da redução do desemprego, que estão vinculados com: a mudança nos padrões político-institucionais de negociação salarial, com os gastos autônomos do governo (massa salarial do setor público, consumo do Estado e o investimento público) e as políticas sociais e distributivas.

O aumento do gasto em seguridade social passou de uma redução em termos nominais (-4\% em 2001 e -2\% em 2002) para crescer 14\% em média anual desde 2003, com aceleração ainda maior a partir de 2006. Outro dado relevante é o gasto público em capital, que vindo de forte redução (-32\% em 2000 e $-22 \%$ em 2002) passou a crescer em torno de $25 \%$ até 2009 (com picos de $87 \%$ em 2003 e $118 \%$ em 2004) (Amico, 2013).

A importância das políticas fiscais expansionistas nessa fase do novo desenvolvimento se torna ainda mais importante quando se considera a pequena importância da desvalorização cambial para o crescimento econômico. Fiorito, Guaita e Guaita (2013) apresentam como os impactos das políticas de desvalorização cambial possuem um impacto muito maior na formação dos preços relativos do que nas taxas de exportação e importação. Dessa forma, o câmbio teria maiores impactos no processo inflacionário do que na determinação do crescimento da economia.

Considerando que a desvalorização cambial tem um efeito muito pequeno no comércio exterior, esse processo só levaria a uma situação favorável da relação entre exportações e importação com a desaceleração do ritmo da economia e não com a realocação de preços. Dessa forma somente uma grande desvalorização

(10) “[...], el resultado crecimiento acelerado de la economía argentina en los años 2000 se basó en la fuerte expansión de la demanda doméstica (consumo e inversión), estimulada (directa e indirectamente) por una activa política fiscal" (Amico, 2013, p. 42). 
cambial poderia impactar na diminuição das importações via uma diminuição dos salários reais e consequente queda da demanda agregada ${ }^{11}$.

A mesma percepção do pequeno impacto do câmbio para o comércio exterior também vale quando se analisa os recentes processos de desequilíbrio externo do país, muitas vezes associados também com a queda do crescimento. Diferentemente do argumento de uma valorização do câmbio, esse desequilíbrio está muito mais vinculado com a própria estrutura produtiva do país. "El desequilibrio externo entre importaciones y exportaciones se produce debido a razones estructurales, entre las cuales la composición de las exportaciones juega un rol central” (Amico, 2013, p. 44).

Dado o forte crescimento econômico na Argentina desde 2003, houve um forte crescimento do investimento e do consumo puxado pela expansão da demanda interna. Entretanto, a estrutura produtiva do país implica em uma forte dependência de peças e bens de capital importados, o que leva o próprio crescimento da economia a condicionar um desequilíbrio externo, independente da taxa cambial. Por isso, em grande parte dos países latinos, o aumento do investimento impacta em um processo de aceleração das importações.

O impacto da estrutura produtiva no desenvolvimento ainda está longe de ser um assunto resolvido, o que é extremamente preocupante em países com estrutura heterogênea ou desequilibrada como na América Latina, em que as commodities possuem grande importância para a exportação. A diferença das elasticidades-renda entre os produtos de exportação e de importação, assim como a forte volatilidade dos preços das commodities, gera um processo de variações cíclicas tanto na capacidade de importação quanto no crescimento e na restrição de divisas. Esse processo tem um forte peso na economia argentina, como foi amplamente abordado pelos economistas estruturalistas, que por meio da voz de Marcelo Diamand ficou conhecido como 'pêndulo argentino'.

Juntamente com o impacto da especialização em commodities, existe um outro elemento extremamente importante: o fluxo dos capitais financeiros internacionais, que muitas vezes é esquecido ou visto como uma mera consequência dessa estrutura produtiva desequilibrada. Apesar dessa estrutura gerar grandes condicionalidades, os altos níveis de endividamento externo devem ser vistos como uma característica estrutural autônoma das economias latinas.

Obviamente a estrutura desequilibrada da Argentina, com altas produtividades na produção de commodities, possui um papel relevante, entretanto, não se pode reduzir a um caso de doença holandesa, já que os fluxos de capitais

(11) "El aumento del tipo de cambio se transmite a los precios, deprime el salario real y consiguientemente la capacidad de gasto de los trabajadores, e induce una recesión que permite regenerar la cuenta corriente exterior" (Canitrot, 1983, p. 23). 
internacionais desempenham uma função fundamental. O processo de acirramento das condições de produção dos países da América Latina na fase atual do capitalismo com sistema financeiro internacional desenvolvido não pode ser analisado sem considerar a dinâmica desses fluxos internacionais de capitais.

Como mostrou Medeiros (2008), existe uma demanda financeira por divisas que não tem relação direta com a estrutura produtiva, mas que surge por meio de uma fragilidade financeira estrutural ${ }^{12}$. Além do processo cíclico causado pela estrutura produtiva desequilibrada há um processo intrínseco de tomada de crédito em excesso, que dado o limite existente nessas economias pelo processo de restrição de divisas, em algum momento será necessário realizar um ajuste na balança comercial não só para conter seu déficit, como para pagar o endividamento excessivo.

No momento de crescimento e de início do ciclo de exportação há um aumento do fluxo de capitais, o qual tem uma grande parte dos financiamentos e investimentos realizados de forma excessiva por um mecanismo de fragilidade financeira. No momento em que há alguma alteração na economia internacional e começa haver um déficit em conta corrente inicia-se um processo de forte saída dos capitais internacionais, dada a maior fragilidade dos países em desenvolvimento em arcar com suas dívidas. Assim se estabelece uma relação com a própria fragilidade de toda moeda periférica em relação a moeda hegemônica, já que qualquer possuidor de ativos líquidos irá preferir manter essa riqueza em ativos de moedas hegemônicas. Vale ainda notar que essa característica existe em algum nível para todos os países com a exceção dos EUA, que ao serem o padrão internacional se tornam por definição a moeda hegemônica de maior credibilidade ${ }^{13}$. Essa tendência, que se agrava fortemente em momentos de maior instabilidade, cria uma tendência crônica dos capitais internacionais fugirem das moedas periféricas (países em desenvolvimento).

Atualmente na Argentina esse processo de fuga de capitais por uma "alta preferência" por ativos externos é evidente. Entretanto, o governo erroneamente tentou coibir esse movimento por meio de restrição de divisas e de ativos em dólar, o que deu vasão a um fortalecimento de um mercado paralelo. Sendo assim, ao invés de coibir a fuga de capitais, levou a um processo descontrolado, já que não se buscou combater o diferencial negativo existente entre os juros internos e externos vinculados à diferença de risco considerado internacionalmente.

(12) "The point here is the recognition that there is a financial demand for currency-a liquidity preference for holding currency - that does not arise by real necessity but by financial fragility" (Medeiros, 2008, p. 73).

(13) Para um estudo mais aprofundado das implicações do dólar como padrão do sistema monetário internacional ver: Serrano (2008). 
Por isso essa forte procura por ativos internacionais como elemento estrutural da economia dos países da América Latina acaba por intensificar os ciclos de preço das commodities e o processo crônico de restrição de divisas. Dessa forma fica evidente a relação dialética existente entre a estrutura produtiva e o sistema financeiro internacional para esses países que, ao mesmo tempo em que apresentam uma forte relação entre esses dois processos, também indica a existência de uma autonomia entre eles. Logo se estabelece uma relação dialética de retroalimentação entre a estrutura agroexportadora e os fluxos financeiros internacionais, que ao mesmo tempo em que redinamizam a economia no sentido da nova divisão internacional do trabalho a fragilizam financeiramente, por meio da autonomia do capital financeiro.

Em suma, nos países em desenvolvimento esse alto nível de dívida externa autônomo ocorre por dois motivos principais: i) um processo de empurrar empréstimos pelos bancos e pelos governos dos países ricos em determinados momentos e ii) pelo próprio excesso de tomada de empréstimo que depende das decisões internas. Dessa maneira fica evidente a importância de entender como e em que direções esses fluxos internacionais entram no país em cada fase de crescimento, assim como a forma com que os grupos econômicos internos investem esse capital.

O momento atual da Argentina é facilmente correlacionado com essa situação, em que depois de um longo período de entrada de capitais durante toda a década de 90 teve um forte revés no começo dos anos 2000, mas que foi logo reestruturado para o início de um novo ciclo. Além da importância de entender como as políticas macroeconômicas específicas ditaram o ritmo interno, é fundamental analisar como se relacionam as várias implicâncias externas com os processos internos.

\section{A formação do neodesenvolvimentismo Argentino}

Não há dúvidas que durante o processo de recuperação o presidente Kirchner e o ministro Lavagna possuíram méritos quanto à política dual de intervenção para manutenção do câmbio competitivo e realização de políticas fiscais expansionistas e distributivas. Como mostramos na seção anterior, as políticas econômicas internas são fundamentais para entender algumas especificidades desse processo, como o próprio ritmo do crescimento econômico do país. Entretanto, não se pode deixar de lado que essas políticas só foram possíveis graças ao ambiente incomum do início dos anos 2000, dado pelo contexto internacional particular de reestruturação da divisão do trabalho e pelo intenso conflito social doméstico, além dos fatores já citados como alta dos preços das commodities e taxa de juros internacional baixa.

Na ciência econômica, tanto ortodoxa quanto heterodoxa, ainda é importante lembrar que os fatores internacionais não se referem somente aos níveis de importação e exportação. Além do fluxo de capitais internacionais, a relação dos 
Estados e a sua inserção no sistema capitalista internacional também produzem efeitos e nuances extremamente relevantes para o entendimento da trajetória do país.

Durante toda a década de 90 a presença do Fundo Monetário Internacional foi um dos grandes marcos para a implantação do Consenso de Washinton, em que colocava a importância da austeridade e das políticas ortodoxas para o bom funcionamento econômico, o que era agraciado com novos pacotes de empréstimos e refinanciamento da dívida. Entretanto, o papel do FMI no processo de recuperação das crises cambiais da virada do século será bem diferente. Como mostrou Damill, Frenkel e Maurizio (2011), a atuação do FMI no período de recuperação da economia argentina pode ser considerada um dos marcos de uma nova forma de atuação do fundo. Enquanto nos anos 90 os refinanciamentos eram realizados com a completa intervenção do FMI, no caso da pós-convertibilidade argentina o fundo não conseguiu participar de forma direta em nenhum momento, o que proporcionou uma liberdade maior para o governo argentino realizar suas políticas.

Quando ocorreu a desvalorização rapidamente se seguiu uma forte aceleração da inflação. Entretanto, o recente ministro Lavagna, contrariando o FMI, implementou um novo plano de estabilização da economia, em que preservava o câmbio flutuante mas com a introdução de intervenções no mercado de câmbio. Apesar da desaprovação do FMI, essas medidas de intervenção foram fundamentais para a estabilização da economia. O FMI julgava que a desvalorização e as políticas fiscais expansionistas iriam desarticular toda a economia, levando à uma grande instabilidade econômica com escaladas hiperinflacionárias, impossíveis de serem contidas. Entretanto, a realidade se mostrou distinta mas, caso fossem seguidas as políticas de austeridade propostas pelo FMI, provavelmente o futuro recessivo descrito pelo fundo se realizaria.

Conforme a recuperação da economia argentina avançava também se fortalecia o seu mercado financeiro, que tinha praticamente desaparecido com a crise. Dessa forma os atores financeiros internacionais começam a voltar ao país, assim como o próprio nível de investimento. A relutância do FMI em participar desse processo se torna cada vez mais complicada o que é completamente colocado em xeque com a desaprovação dos EUA na insistência do fundo em intervir diretamente na economia para a concessão de refinanciamento da dívida. Em sentido oposto ao modus operandi do fundo durante as décadas de 80 e 90, "nowadays, the functions of the IMF in the international financial system are probably more undefined than ever before and the institution lacks precise orientation" (Damill; Frenkel; Maurizio, 2011).

É inegável a alteração das atuações dos órgãos políticos e econômicos do sistema internacional nos anos 2000 em relação as décadas anteriores, principalmente nos primeiros anos do século. Os EUA que inquestionavelmente exercem enorme influência nas instituições internacionais criadas no pós-guerra 
passavam por um período extremamente complicado de fragilidade política. Desde os atentados de 11 de setembro de 2001 os esforços da política internacional norteamericana se voltaram para a resolução desse conflito externo, que se agravou com o início da Guerra no Iraque em março de 2003.

Assim como o panorama externo foi relevante para o processo de recuperação da crise de pós-convertibilidade, a dinâmica dos movimentos sociais e dos grupos econômicos será fundamental. A relação entre os grupos internos apresentou nos primeiros anos pós-convertibilidade uma dinâmica relativamente nova na história da Argentina. Tradicionalmente na economia argentina há um claro conflito entre a burguesia nacional (representante da indústria nacional), dos grupos agroexportadores (muitas vezes vinculados com o ideário dos capitais estrangeiros) e a classe trabalhadora.

Principalmente durante os anos 90 houve um processo de ruptura na formação socioeconômica clássica da Argentina, além do processo de desindustrialização, houve uma forte entrada das multinacionais, que apesar de comporem a indústria argentina são completamente vinculadas ao setor externo, tanto em termos de suas decisões de investimento quanto no destino dos lucros e da sua lógica de valorização. Mesmo o grupo dos agroexportadores que anteriormente eram diversificados, nos anos finais da década voltou-se fortemente para a expansão do agronegócio. Dessa forma, houve um enfraquecimento da burguesia nacional, ou em outras palavras, da indústria nacional argentina como um ator forte na disputa da política econômica.

O enfraquecimento dessa burguesia nacional foi latente com o estouro da crise e a quase estagnação do Estado e da economia. Juntamente com esse enfraquecimento, os outros dois grupos passam a ter cada vez mais um papel decisivo na conjuntura argentina, dada a dinamicidade crescente dos agroexportadores e a maior combatividade dos movimentos sociais.

A megadesvalorização logo após o período de convertibilidade e as políticas fiscais expansionistas e distributivas terão um papel importante nesse processo, pois irá fortalecer essa nova formação ao mesmo tempo em que irá recompor as taxas de lucro da produção industrial argentina e promover o crescimento da demanda agregada. Será essa recomposição e o forte aquecimento da demanda que levaram alguns economistas a acreditar no maior potencial do novo desenvolvimentismo em colocar a estrutura argentina nos trilhos do desenvolvimento. Porém, os percalços (contradições) da economia capitalista são muito mais complexos do que meros fenômenos de demanda, o que condiciona tanto os efeitos de uma determinada política macroeconômica quanto sua própria continuidade.

O câmbio desvalorizado e as políticas expansionistas recompuseram a indústria argentina, mas logicamente com forte concentração na indústria que teria alguma competitividade internacional. Em um país com uma estrutura produtiva 
desequilibrada, a indústria que teria algum potencial de concorrência internacional evidentemente seria a indústria ligada aos manufaturados de origem primária, não só os vinculados com o grupo agroexportador como também os com baixa dinamicidade tecnológica e produtiva para os demais setores da economia.

Outro fator importante para esse fortalecimento foi o grande fluxo de capitais para essa produção, que desde a década de 80 promoveu grandes alterações tanto no campo como na indústria que secunda a atividade agroexportadora. Dessa forma, grande parte da entrada dos capitais internacionais teve como destino o financiamento da instalação de um grande número de empresas multinacionais e do estabelecimento dos grandes latifúndios com forte inversão de capital. O que evidencia uma relevância dos fluxos financeiros internacionais em relação a um típico processo de doença holandesa.

Por isso, apesar do crescimento industrial no novo desenvolvimentismo ter sido tão alardeado pelo governo e por alguns economistas, não se passou de uma industrialização agroexportadora com um impacto muito restrito, sem possibilitar as reformas mais profundas na estrutura produtiva e social do país. Em 2010 o país possuía um superávit de US\$ 11 bilhões em produtos primários e de US\$ 22 bilhões em manufaturados de origem agrícola, enquanto apresentaram um déficit de US\$ 21 bilhões em manufaturados de origem industrial.

Quando comparado com a década de 90, vemos que há uma continuidade na expansão tanto da estrangeirização da produção quanto da concentração do capital no campo. Seguindo o processo da década de 90 houve uma concentração de $24,4 \%$ na quantidade de propriedades rurais com um aumento de $19,4 \%$ na média de hectares por propriedade, indo de 518 de 2002 para 619 em 2008 (Censo Nacional Agropecuário Argentino (2002-2008)). O saldo comercial argentino mostra não só a dependência dos produtos do setor primário, como um grande aumento desse processo. Os superávits aumentaram no final da década, em relação aos dois primeiros anos, justamente nos produtos primários ou manufaturados de origem agrícola, enquanto houve um aumento no déficit de produtos manufaturados de origem industrial.

Essa estrutura do superávit argentino é mais alarmante ainda quando se coloca em questão os níveis altíssimos dos preços das commodities, tendo seu valor índice triplicado de 2002 a 2008 (dados do Indec), o que possibilita uma total reversão da situação com uma mudança no mercado internacional. O grande aumento desses preços se deve à entrada definitiva do mercado asiático no comercio mundial, que com amplo destaque chinês, possui uma grande dependência de produtos primários. Entretanto, a China possui várias iniciativas para buscar solução a essa dependência, o que põe um risco ainda maior à manutenção desses preços, o que tem sido vital para o superávit argentino. 
Atualmente as indústrias que possuem relevância na Argentina não constituem uma relação de oposição com os grupos agroexportadores como ocorria no passado. Diferentemente do período do Nacional Desenvolvimentismo em que o governo buscava um fortalecimento doméstico por meio da indústria nacional e dos trabalhadores se opondo ao grupo agroexportador, na primeira década do século XXI a indústria é composta de manufaturados primários para exportação, o que obviamente não causa uma oposição com o modelo agroexportador. Em 2009, a indústria de produtos alimentícios e bebidas foi responsável pela ocupação de $30 \%$ da mão de obra na indústria, apresentando um crescimento no número de trabalhadores de 4\% em relação a 1997 (conforme dados do Indec). A indústria de substâncias químicas e produtos químicos (ligada à produção de agrotóxicos, fertilizantes e sementes) obteve nesse mesmo período um crescimento de $8 \%$. Em contraste, podemos observar as indústrias mais tradicionais, ou com maior dinamicidade, como a de máquinas e aparatos elétricos com redução de $17 \%$ e a de veículos automotores ${ }^{14}$ com um decrescimento de $6 \%$.

Por isso o fortalecimento da indústria na Argentina atualmente não vai contra o setor agroexportador, como ocorria anteriormente, mas sim no mesmo sentido, já que essa indústria é formada principalmente por manufaturados de origem primária.

Com relação à classe trabalhadora os longos anos do neoliberalismo e de compressão dos ganhos sociais levou a um fortalecimento histórico das suas lutas e da sua combatividade. Houve na Argentina um forte processo de reconfiguração das lutas sociais, com um destaque para o movimento dos piqueteros e da UTD (Unión de Trabajadores Desocupados). Apesar do fortalecimento dessas lutas, há uma clara alteração no seu conteúdo, cada vez mais deixando de ser um conflito contra o capital em geral (na figura da própria empresa capitalista), para uma disputa por melhores condições de vida, que se expressa na figura do Estado ${ }^{15}$.

(14) A pauta de exportação industrial argentina possui uma grande exceção na sua relação com o Brasil, a qual se particulariza mais ainda por se tratar basicamente de componentes automotores, sendo $80 \%$ dessa produção exportada para esse seu importante vizinho. Entretanto, essa indústria perde cada vez mais sua dinamicidade, dada a desarticulação de toda cadeia de valor agregado devido à enorme participação estrangeira no fornecimento de peças, o que leva a se estabelecer muito mais como simples montadoras do que como indústrias (Azpiazu; Basualdo; Schorr, 2001).

(15) A alteração da substância dos movimentos sociais não é algo exclusivo da Argentina, muito menos pontual. A percepção dessas alterações pode ser caracterizada de forma pioneira nos trabalhos da escola de Frankfurt, tanto na obra de Marcuse como em trabalhos de Habermas já nos anos 80. De acordo com essa escola de pensamento, essa alteração ocorre ligada ao próprio movimento sindical, que passa a tentar se integrar ao Estado e a dirigir suas ações não mais para se opor a ele, mas sim para conseguir um aumento de consumo da classe trabalhadora. O movimento sindical se instrumentaliza para agir dentro do Estado e dessa forma lutar por maiores garantias de consumo para sua classe. A percepção desse movimento de alteração dos conflitos sociais na estrutura do capitalismo advém da esfera internacional, ou seja, dos avanços do próprio sistema capitalista em geral. Entretanto, como veremos na seção seguinte, essas modificações apesar de parecerem abstratas apresentam modificações concretas na dinâmica da economia argentina, como se exemplifica nos novos contextos de barganha salarial e briga distributiva, que irão impactar diretamente nos processos inflacionários recentes. 
$\mathrm{Na}$ Argentina o percurso recente dos sindicatos representa claramente esse processo de alteração das lutas políticas. Durante toda a década de 90 e principalmente nos anos 2000 há um movimento inverso das principais forças sindicais. Enquanto vários dos antigos sindicatos perdem força e importância no quadro político argentino, o sindicato dos caminhoneiros passa a ter uma importância crescente, o que pode ser visto pelo próprio número de afiliados passando de $70 \mathrm{mil}$ em 1992 para 200 mil em 2011.

O Sindicato dos Caminhoneiros se fortaleceu principalmente nas províncias por sua capacidade de parar a estrutura produtiva do país, extremamente dependente das rodovias para o escoamento de sua principal produção, cereais (soja e milho) para exportação. O líder do Sindicato dos Caminhoneiros, Hugo Moyano, se torna Secretário Geral 'de la Confederación General del Trabajo de la República Argentina' (C.G.T). Na figura de Moyano terá uma representatividade forte, que com amplo apoio durante os primeiros anos do governo Kirchner será um dos elementos essenciais dessa coalização neodesenvolvimentista, se tornando uma ferramenta de barganha contra os agroexportadores nas principais negociações. Até 2011, Moyano teve uma forte ligação com os presidentes Nestor e Cristina Kirchner, obtendo um papel importante como chefe do Conselho de Salários (um conselho consultivo oficialmente sancionado) garantindo uma posição de barganha coletiva mais forte e com aumentos frequentes no salário mínimo. O cargo de chefe do Conselho de Salários obtido por Moyano será extremamente representativo da forma de luta social que se configura no neodesenvolvimentismo argentino, no qual não se passa por reformas estruturais, mas por ganhos reais no consumo via crescimento do salário nominal.

O Nacional Desenvolvimentismo na América Latina (como o caso do peronismo na Argentina iniciado na década de 1940), do ponto de vista social, teve um grande papel de garantia dos direitos trabalhistas, o que representou um grande aumento nos níveis de salário real e do crescimento da demanda agregada, levando a altos patamares de ocupação e de salários reais. De certa forma, o governo intervia mais diretamente nas determinações das taxas de lucro e de salário por meio do estabelecimento formal de direitos trabalhistas e de políticas diretamente intervencionistas na estrutura produtiva, tanto com câmbios múltiplos como com o estabelecimento de empresas estatais em setores específicos. Entretanto, no Neodesenvolvimentismo, apesar da grande importância da classe trabalhadora nessa coalizão e dos níveis históricos de distribuição de renda, a forma como o governo intervém nas questões sociais é diferente.

Não houve avanços significativos no governo Kirchner em relação a mudanças estruturais na economia do país, mas houve avanços inquestionáveis do ponto de vista social, que ocorreram por políticas sociais que garantissem o consumo dos trabalhadores e uma maior distribuição de renda. O governo implementou uma política salarial com maior abertura de negociação, reabrindo as negociações 
coletivas e aumentando constantemente os salários mínimos com expansão dos empregos públicos. A participação dos salários da renda subiu de cerca de $30 \%$ em 2003 para $42 \%$ em 2010 segundo o Centro de Estudios sobre población, empleo y desarrolo (CEPED), enquanto o índice de Gini passou de 54,72 em 2002 para 44,5 em 2010 (de acordo com o Indec). Também se ampliou significativamente a cobertura dos setores mais humildes, combatendo a pobreza no país. Além dessas políticas implantadas também é inegável o contraste existente entre a etapa atual de melhoras e o período anterior de implantação das reformas neoliberais (Katz, 2010).

Entretanto, mais profundamente do que o discurso dos macroeconomistas do novo desenvolvimento, o que temos é um fortalecimento do crescimento da economia via agroindústria e uma melhora em algumas variáveis sociais devido a políticas de expansão do consumo. O próprio desenvolvimento dessa estrutura está ligado com as políticas de câmbio desvalorizado, as políticas fiscais expansionistas e a entrada de capitais internacionais sem regulação que, ao mesmo tempo em que garantem essa expansão agroindustrial, garantem também as divisas necessárias para a manutenção do consumo e da industrialização.

Porém, longe de se apresentar como uma mudança estrutural no país em que se teria alcançado um nível de desenvolvimento integral e autônomo, cada vez mais é possível notar que não passa de mais uma fase do pêndulo argentino ${ }^{16}$, em que há um fortalecimento do setor primário e o acirramento do processo distributivo e inflacionário. Apesar do pêndulo continuar o seu movimento, ele agregou novos elementos, já que mesmo sendo um momento de primazia da produção de commodities para exportação, há forte presença da agroindústria e de uma coalização social (com incorporação de ampla parte da classe trabalhadora) por meio das políticas de garantia do consumo.

Durante a fase de recuperação pós-convertibilidade o casamento entre os grupos agroindustriais, os trabalhadores e o governo ocorrem em grande harmonia. Até meados de 2007 pode-se caracterizar como o período de ouro desse novo desenvolvimentismo argentino, no qual atingiu taxas formidáveis de crescimento econômico com inflação controlada e grande coalizão social. No entanto, o ano de 2008 pode ser considerado o ano limite dessa configuração, pois já começa a ficar claro as principais contradições contidas no modelo, como a própria impossibilidade de resolver questões de desenvolvimento social e produtivo baseado em uma reprimarização da economia com fortalecimento dos grupos agroexportadores.

\section{O acirramento do novo desenvolvimentismo}

O período de recuperação da Argentina pós-crise de convertibilidade pode sim ser considerado um momento singular na história de desenvolvimento do país,

(16) Menção à analogia criada por Marcelo Diamand para descrever o movimento da economia Argentina relacionado com a sua estrutura produtiva desequilibrada, conforme apresentamos no capítulo anterior. 
mas longe de ser devido ao alcance de um período de desenvolvimento integral. A singularidade do período está na forte coalização político-social interna, dada pela crise da convertibilidade, juntamente com o período pré-crise financeira internacional de 2008, marcado por enormes fluxos de capitais internacionais e pelo crescimento espetacular da China, o que impactou na elevação dos preços das commodities e permitiu um conjunto de políticas fiscais expansionistas e distributivas. Entretanto, como iremos explorar nessa seção, essa formação específica não irá se sustentar durante toda a década, apresentando já nos últimos anos grandes cisões e mudanças na configuração político-econômica.

O marco dessa alteração dentro do período novo-desenvolvimentista na Argentina pode ser considerado em 2008, com o processo histórico de disputa entre o setor agroexportador e o governo pela implantação da lei de retenções móveis (Resolución 125). Até o começo de 2008 havia uma forte estabilidade entre os principais grupos do país, sem que o governo se opusesse ao setor agroexportador, enquanto esse grupo apoiava a expansão de políticas sociais que garantisse um aumento de consumo da população.

A partir de 2007 a economia Argentina não se encontrava mais em um período de recuperação, como pode ser visto pelos níveis "normais" de utilização da indústria em cerca de $80 \%$ já no final de 2006 (Vernengo, 2011). A partir de 2006, mas principalmente durante 2007 e 2008, há uma elevação brusca nos preços das commodities exportadas pela Argentina, o que acentuou ainda mais a reprimarização da economia que vinha ocorrendo durante todo o período de recuperação.

O governo, com o discurso de frear esse processo de expansão exagerada das commodities, lança em março de 2008 o já mencionado projeto de retenções móveis, que consistia na taxação entre $7 \%$ e $9 \%$ das exportações de soja, milho, trigo e girassol conforme a variação do preço desses produtos. Logo após o lançamento do projeto no senado já se inicia um intenso conflito entre o governo e o grupo liderado pelo setor agroexportador, que será apenas o primeiro de uma série de disputas entre os mais variados temas ${ }^{17}$.

(17) No final de 2009 ocorreu uma grande discussão econômica e política em torno do 'Fondo del Bicentenário', o qual se tratava da criação de um fundo especial para garantir o pagamento da dívida externa. Esse seria construído com as reservas do Banco Central mediante a um empréstimo com taxas de juros controladas, para reduzir a sobrecarga financeira no Tesouro. O argumento da Presidente Cristina Kirchner se baseou na situação emergencial e particular da crise financeira mundial de 2008, que paralisou a economia mundial e diminuiu a arrecadação do país. Assim, ao invés de conseguir financiamento por meio de mais endividamento externo (com taxas de juros maiores), foi proposto um empréstimo concedido pelo Banco Central. Entretanto, as disputas internas do país, com um amplo apelo de constitucionalidade e no Congresso Nacional, barraram a criação desse fundo e a maior liberdade do governo para dar continuidade às políticas econômicas e sociais. Outra grande disputa dentro do modelo novo-desenvolvimentista argentino tem se dado no conflito entre os principais grupos midiáticos e o governo. Dessa forma, Cristina Kirchner tenta desde 2010 implantar uma grande reforma no setor jornalístico, o que tem causado uma grande batalha campal com o jornal Clarin por todo o país. 
A importância dessa disputa será amplamente alardeada por vários analistas na Argentina, dada a sua representatividade como marco simbólico de uma mudança de rumo para o padrão de desenvolvimento do país. O resultado desse conflito colocou muitos condicionantes de como se dariam as principais disputas, que apesar do peso do setor agroexportador teria a contradição de um governo mais intervencionista, que ao invés de tentar coibir a exportação pretenderia utilizá-la para alçar voos desenvolvimentistas maiores.

Es así que [...] partiremos de la idea de que la disputa por las retenciones móviles actuó como punto de partida de un proceso en el cual se puso en juego la definición sobre el modelo de Estado-nación en Argentina, generándose de este modo una disputa por la dirección del Estado (Esteve, 2011).

Durante os 129 dias, de 11 de março de 2008 até 17 de julho de 2008, quando o senado revogou o projeto oficial, houve uma intensa polarização no país, com uma intensa disputa política ideológica. O governo nacional se defendia das fortes acusações de confisco argumentando da importância da Resolución 125 para a continuidade do projeto desenvolvimentista, pois teria como objetivo evitar que o forte aumento dos preços das commodities nos últimos anos impactassem os preços internos. Dentro dessa perspectiva, o governo apresentava a medida como uma maneira de amenizar os impactos do aumento externo dos alimentos na economia nacional. O então ministro Martín Lousteau, defendia a importância de desvincular os preços internacionais dos preços internos, o que já começava a pesar na economia argentina, cada vez mais dependente das exportações de grãos. Além desse fator importante nos preços internos, a medida visava também incentivar uma contenção do processo de sojizacion da economia, que se tornava cada vez mais concentrada.

O setor agropecuário, por sua vez, obteve uma união histórica na economia argentina, colocando do mesmo lado organizações historicamente opostas (SRA, FAA, Coninagro e CRA) com o discurso de que o governo estava se utilizando de meios confiscatórios. Esses grupos alegavam a inviabilização da produção de oleaginosas se a medida fosse vigorada. Esse argumento se alastrou pelo país, com um forte peso ideológico e da nova importância do campo, mesmo nas zonas rurais. Apesar de inúmeros estudos apresentados sobre o crescimento muito superior dos preços em relação aos novos impostos ${ }^{18}$, o argumento do confisco às rendas agrárias prevaleceu na sociedade argentina.

Como tentamos mostrar ao longo desse trabalho, nos últimos anos a Argentina passou por um intenso processo de reprimarização da sua economia, o que ocorreu

(18) “De acuerdo con las estimaciones disponibles, la rentabilidad por hectárea de soja con posterioridad a la vigencia del nuevo régimen de retenciones móviles alcanzó, en pesos constantes de 2007, 1223\$ por hectárea, mientras que el promedio de 2007 había sido, medido en la misma forma y para idéntico cultivo, de 846\$ por hectárea. Es decir, que a pesar de la aplicación de las nuevas retenciones, el ingreso por hectárea de los productores se incrementó en un 45\%" (Basualdo; Arceo, 2009). 
com uma forte concentração do campo e grande entrada de capital internacional, principalmente na construção da indústria complementar à essa produção agroindustrial. Entretanto esse processo acaba por aumentar a renda da terra e colocar os pequenos e médios proprietários na posição de rentistas, em outras palavras, os produtores menores não podem competir em custos com os grandes grupos, por isso são levados a abandonar a produção e arrendar o campo para alguma grande empresa capitalista. Por isso, mesmo as organizações historicamente contrárias aos grandes grupos capitalistas se uniram nesse momento, dado a sua nova posição de rentista e, portanto, com participações na renda da exportação de oleaginosas. Dessa forma, esses pequenos produtores não são mais uma classe usurpada da terra, mas uma nova classe média que se identifica muito mais com vínculos empresariais.

Essa restruturação do campo argentino, com uma forte concentração e saída dos pequenos proprietários para a cidade por meio de um processo de aburguesamento dos fazendeiros medianos ${ }^{19}$, terá um forte peso na estrutura política argentina. Historicamente os pequenos e médios agricultores se opunham à oligarquia pampeana, pois enquanto esse grupo possuía fortes privilégios políticos e acesso ao mercado internacional, os pequenos se encontravam muito mais voltados para o abastecimento do mercado doméstico, o que lhes colocava muitas vezes no campo político dos nacionalistas e dos trabalhadores. Entretanto houve uma brusca mudança nesse quadro político do campo, com uma junção de todas as entidades agropecuárias contra o governo ${ }^{20}$.

Será exatamente esse médio proprietário que terá maior visibilidade e atuação durante os conflitos com o governo. Com ampla capacidade de mobilização, por meio do discurso de confisco das rendas, essa nova classe média derrotou o governo, mas por fim os grandes ganhadores desse processo serão os grandes proprietários agroexportadores. Com a revogação da medida foram retiradas também as taxações

(19) "Además, muchos de los pequenos y medianos produtores pampeanos se convierten en rentistas o 'cuasi-rentistas', ya que se ha dado un doble proceso de valorización de la tierra y descapitalización y reducción del peso del trabajo propio” (Basualdo; Arceo, 2009).

(20) "A diferencia de los años 90, los contratistas que a su vez son rentistas no enfrentan ninguna amenaza de quebranto. Por eso frecuentemente afirman que las retenciones "conspiran contra su estilo de vida", al empujarlos a sustituir el trabajo directo por el alquiler del campo. En ese caso pasarían a vivir de un alto ingreso, en condiciones muy alejadas de los padecimientos que soporta la mayoría de la población. El nuevo contratista tiene muy pocas afinidades con el viejo chacarero que forjó la Federación Agraria. Por esta razón la demanda de anular las retenciones móviles tuvo primacía sobre el programa histórico de reforma agraria y Junta Nacional de Granos. Tampoco los antiguos cooperativistas se parecen a los empresarios medianos que controlan CONINAGRO. A su vez, los grandes propietarios de CRA se han convertido en grandes burgueses y los latifundistas ganaderos de la Sociedad Rural en agro-capitalistas. Como consecuencia de estos cambios, solo un porcentaje mínimo de los productores mantuvo su vieja afiliación gremial, lo que explica la gran autonomía que demostraron las asambleas de auto-convocados" (Katz, 2008). 
que variavam com o tamanho da exportação ${ }^{21}$, dessa forma enquanto um pequeno produtor de 200 toneladas passou de uma renda estimada de 29.280 pesos para 26.839 pesos, um grande produtor passou de 554.460 pesos para 670.740 pesos, conforme estimativas do jornal Página 12 (Donda; Merchán, 2008).

O conflito por retenciones moviles será, portanto, o grande marco da disputa que se instala no modelo novo desenvolvimentista argentino, em que as novas políticas do governo se chocam diretamente com as intenções dos setores agroexportadores. A intenção do governo, mesmo quando esse conflito já se encontrava acirrado, nunca foi desestimular ou emperrar a expansão da exportação de commodities, pelo contrário, sua intenção foi de expandir essa produção, mas com maior capacidade de intervenção nessa renda para poder dar continuidade a suas políticas de manutenção do consumo e de defesa de alguns setores da burguesia nacional.

A intensificação desse conflito entre os principais grupos políticos econômicos no interior do bloco histórico do novo desenvolvimentismo pode ser ilustrada, ou representada, pelo processo atual de elevação da inflação na Argentina, que tem no conflito distributivo sua grande expressão.

O aumento de preços deve ser entendido como uma das representações da própria estrutura produtiva-política da Argentina. Obviamente a determinação do preço em uma sociedade capitalista não deixaria de conter a questão essencial entre a disputa capital e trabalho, entretanto quando analisamos esse processo não devemos reduzi-lo para a esfera da distribuição, dessa forma tanto a estrutura produtiva quanto as relações distributivas de classe interna e externa possuem fortes condicionantes.

A discussão sobre os determinantes da volta das altas taxas de inflação na Argentina tem sido acalorada, com muitas opiniões divergentes, a qual ganha contornos mais dramáticos com as atitudes do governo de criar novos índices que mascaram a real situação do país. Em 2007 o governo rejeitou o cálculo anterior e passou a realizar um novo índice. Várias consultorias passaram a mensurar a variação de preços para confrontar com o governo, o que tem trazido altas divergências. Enquanto o governo divulga valores em torno de $10 \%$ ao ano, várias

(21) “Los ganadores inmediatos serán los exportadores y sobre todo los grandes productores, que pagarán un impuesto inferior al estipulado en el proyecto de ley que rechazó el senado. Esta iniciativa incorporaba una segmentación del impuesto por volumen de producción, que el gobierno primero concedió a quiénes producen menos de 500 toneladas. Luego introdujo una escala que situaba las retenciones en un $30 \%$ hasta 300 toneladas, $35 \%$ hasta 750 toneladas y 40\% por encima de 1500 toneladas. Esta diferenciación quedó sepultada con la derogación del decreto oficial, determinando una clara pérdida para quiénes fueron el estandarte de la revuelta rural" (Katz, 2008). 
consultorias apresentam valores em cerca de $30 \%{ }^{22}$. Não por acaso o tema da inflação tem polarizado grande parte do debate atual no país.

A grande diferença das teorias e analises existentes sobre o processo inflacionário (principalmente sobre como combatê-lo) se deve basicamente aos profundos efeitos distributivos. As principais visões podem ser agrupadas entre inflação de custos e inflação de demanda, grosso modo vinculadas com teorias heterodoxas e ortodoxas respectivamente. Essa última, entretanto, é rapidamente rechaçada quando se analisa mais detalhadamente a estrutura produtiva e de preços da Argentina.

Como mostrou Vernengo (2011) a capacidade utilizada da indústria argentina está longe de alcançar o seu limite, já que em 2011 atingiu apenas $80 \%$. De 2003 a 2010 o PIB cresceu ao redor de $60 \%$, enquanto o investimento no mesmo período foi de $147 \%$, o que indica uma forte tendência de ajuste da economia ao crescimento da demanda. A argumentação da inflação de demanda apenas esconde o interesse de aumento dos juros pelos grupos financeiros e o fortalecimento de um conjunto de políticas austeras que impediriam a continuidade das políticas distributivas e da implantação de reformas mais profundas no país, como o caso das retenciones moviles.

Uma das abordagens mais frutíferas sobre o crescimento da inflação atual na Argentina consiste em mostrar como esse processo está vinculado à uma dinâmica de desvalorização cambial com conflitos distributivos (ver: Amico, 2008 e Amico; Fiorito, 2010a, 2010b) ${ }^{23}$. As políticas macroeconômicas do governo argentino desde a recuperação pós-convertibilidade, como mostramos na seção anterior, consiste em manter o câmbio alto (atraindo divisas, dados os preços favoráveis do mercado internacional) e realizar políticas sociais via manutenção do consumo popular elevado. Obviamente esse quadro coloca um aumento nos custos produtivos, o que desencadeará na velha disputa distributiva com explosão inflacionária ${ }^{24}$.

(22) A grande maioria das análises político-econômicas acusa com grande veemência essa atitude do governo, pois teria como objetivo iludir o povo enquanto seus salários seriam corroídos. Mas atualmente alguns analistas defendem que essa atitude do governo não teria um impacto tão grande para os trabalhadores, pois estes reajustariam os salários com as taxas mais "verdadeiras" da inflação, dado a grande divulgação desses dados pelos outros institutos não oficiais e pela alta combatividade atual dos trabalhadores e sindicatos argentinos. Entretanto, no caso dos juros da dívida, o país faz todos pagamentos com os juros oficiais, o que esconderia um relativo calote da dívida. Apesar de um ponto de vista interessante essa abordagem precisa de mais atenção e avaliação para ser defendida.

(23) "El agravamiento del conflicto distributivo - con su efecto inflacionario vía costos y su alcance corrosivo de la competitividad -, le sería entonces inherente. A su vez, la aceleración inflacionaria originada en el ajuste cambiario se ve estimulada por el propio proceso de crecimiento, ya que la expansión fortalece a los actores en conflicto (empresarios y sindicatos) y amplía los límites que impone al pass-through una situación recesiva" (Amico, 2008, p. 41-42).

(24) Para uma maior compreensão desse processo inflacionário dado por conflito distributivo ver Serrano (2010). 
O governo, respondendo às fortes demandas sociais, implanta vários programas distributivos e de aumento dos salários, mas que são logo contornados por aumentos de preços, o que torna estável (ou até com redução) o salário real. Os grupos capitalistas mais concentrados asseguram benefícios elevados, com remarcações que somente eles podem realizar. Portanto, se estabelece uma inflação que somente garante o ganho da classe dominante, o que acaba por barrar qualquer intenção de crescimento pela demanda agregada.

As causas da inflação argentina evidentemente são mais profundas do que uma inflação de demanda, como pode ser visto claramente pelo conflito distributivo que polariza historicamente a economia argentina. Entretanto, esse conflito é apenas o reflexo da questão real que está por trás dessa inflação.

$\mathrm{O}$ caso argentino mostra claramente como os elementos na economia capitalista se relacionam, em que o conflito distributivo se torna fundamental para compreender a conjuntura econômica, mas não podendo esquecer que a distribuição da renda passa sempre pelas condicionalidades do modo de produção. Marx, no seu último trabalho escrito, já lembrava a importância de entender as condicionalidades impostas pela produção nas implicações da distribuição de renda na economia, parecendo adivinhar os rumos que as teorias econômicas tomariam.

Mesmo prescindindo do que fica exposto, é equivocado, em geral, tomar como essencial a chamada distribuição e aferrar-se a ela, como se fosse o mais importante. A distribuição dos meios de consumo é, em cada momento, um corolário da distribuição das próprias condições de produção. [...] O socialismo vulgar (e através dele uma parte da democracia) aprendeu com os economistas burgueses a considerar e tratar a distribuição como algo independente do modo de produção, e, portanto, a expor o socialismo como uma doutrina que gira principalmente em torno da distribuição. Uma vez que desde há muito tempo já está elucidada a verdadeira relação das coisas, porque voltar a marchar para trás? (Karl Marx, Crítica ao programa de Gotha, p. 8).

A grande questão na economia atual argentina remete às mudanças oriundas do campo nos últimos vinte anos, tanto com relação ao padrão interno quanto internacional. A renda da terra deve ser um tema central de discussão na economia argentina. Como tentamos apresentar ao longo desse trabalho, a entrada da Ásia em geral e da China em específico como grande ator no mercado mundial, juntamente com o grande fluxo de capital internacional pós-neoliberalismo, levou a uma grande remodelação do sistema econômico internacional, o que pode ser visto nos casos específicos dos países latinos, como da Argentina, no forte aumento dos preços das commodities, o que também foi fortalecido por um forte processo especulativo.

O forte aumento nos preços das commodities e a grande entrada de capitais nesses setores agroexportadores gerou uma remodelação interna, o que se dá por meio da unidade das relações sociais produtivas, ou seja, envolvendo tanto os 
conflitos de classe e distributivo, quanto a sua própria estrutura produtiva. A estrutura produtiva deve ser vista também como um elemento político, assim como a relação de classe também deve ser compreendida como um elemento econômico. O processo de financeirização do campo, com grandes investimentos de empresas multinacionais e grandes fluxos de capitais atraídos pelo aumento dos preços dos produtos agropecuários, especialmente soja e milho, levou ao aumento continuado da renda agrária, dado a grande fertilidade da região pampeana, o que irá perpassar alterações estruturais em toda dinâmica social argentina.

A forma como a renda agrária se forma e como ela passa a encadear o conflito distributivo deve ser o ponto nodal de articulação da economia argentina e não o contrário, como seria uma análise que parte da desvinculação entre a produção e a distribuição. Por isso nesse trabalho tentamos, por meio da construção das principais mudanças econômicas, entender os processos de disputa na economia argentina e como esses processos político-sociais também acabam por direcionar a economia do país.

\section{Apontamentos finais}

O próprio modo de produção atual da Argentina condiciona em grande parte essa dualidade das políticas e análises atuais, com uma forte bipolaridade entre um setor agroexportador extremamente capitalizado e um movimento social fortemente combativo. Marcelo Diamand, de forma pioneira, já mostrava como essa relação entre a estrutura produtiva, a relação cambial e o conflito distributivo acabam por condicionar em grande parte os movimentos da economia argentina. Como analisou Diamand, a estrutura produtiva heterogênea condiciona uma trajetória de desenvolvimento pendular, em que há uma alternância entre momentos de distribuição de renda com restrição de divisas e de crescimento econômico sem coesão social.

Mais do que nunca o pêndulo parece pesar sobre a economia argentina. A inflação e o conflito distributivo que aparecem como os grandes problemas atuais do país, apenas camuflam a grande questão: a extrema concentração produtiva imposta pelo setor agroexportador em acordância com a nova divisão internacional do trabalho. Entretanto, mais do que nunca se necessita e, essa é uma das intenções desse trabalho, esclarecer do que exatamente se trata essa questão produtiva.

Muitas análises, mesmo heterodoxas, ao perceberem a importância desse fator, a consideravam como um processo de doença holandesa, que dado suas diferenças de elasticidades cambiais levariam a um processo cíclico de restrição de divisas. Mas o problema é mais profundo. A questão da produção na América Latina deve ser vista como dentro de um modo de produção capitalista, ou seja, como um sistema produtivo inserido no sistema capitalista internacional. É somente dessa 
forma que pode-se compreender como esse modo de produção condiciona outros dois elementos fundamentais, que também possuem fatores de autonomia: o fluxo internacional de capitais e a formação de grupos econômicos internos.

Uma política de crescimento econômico pode ser realizada pela esquerda ou pela direita, mas se o seu modo de produção, sua inserção internacional, continuar sendo de agroexportador, não haverá meios de gerar uma mudança estrutural que colocaria a economia em um outro patamar de desenvolvimento. Esse é um dos grandes erros dos economistas que acreditaram no novo desenvolvimentismo, achar que o sistema produtivo e a inserção internacional dos países da América Latina se igualariam aos países Asiáticos (por exemplo) simplesmente por meio da mudança dos preços relativos via políticas cambiais com aumento do gasto do governo em programas socais e de aumento do consumo. Nem as políticas cambiais elaboradas inicialmente pelos novos desenvolvimentistas, nem a sua conjunção com políticas expansionistas (como evidenciado na primeira seção) levou a economia argentina a um novo padrão que pudesse ser chamado de desenvolvimento.

\section{Bibliografia}

AMICO, F. Argentina 2002-2008: ciclo económico, inflación y crecimiento. OIKOS, Rio de Janeiro, v. 7, n. 2, 30 nov. 2008. Disponível em: http://www.revistaoikos.org/seer/index.php/oikos/article/view/118.

AMICO, F. Crecimiento, distribución y restricción externa en Argentina. Circus, Revista Argentina de Economía, n. 5, Mayo 2013.

AMICO, F.; FIORITO, A. Inflácion: la política en acción. Pagina 12, 7 Fev. 2010a. AMICO, F.; FIORITO, A. El largo de la convertibilidad: política fiscal e 'independencia' del BCRA. Circus, Revista Argentina de Economia, Jan. 2010b.

ASTARITA, R. Desarrollo capitalista, renta y conflicto en el agro argentino. In: BONNET, Alberto (Comp.). El país invisible: debates sobre la Argentina reciente. 1. ed. Buenos Aires: Continente, 2011.

AZPIAZU, D.; BASUALDO, E.; SCHORR, M. La industria Argentina durante los años noventa: profundización y consolidación de los rasgos centrales de la dinámica sectorial post-substitutiva. Buenos Aires: Área Economía y Tecnología, FLACSO, 2001.

BASUALDO, E.; ARCEO, N. Características estructurales y alianzas sociales en el conflicto por las retenciones móviles. In: ARCEO, E.; BASUALDO, E.; ARCEO, N. La crisis mundial y el conflicto del agro. Buenos Aires: Editorial La Página, 2009. 
BOITO JR., Armando. A nova burguesia nacional no poder. In: BOITO JR., Armando; GALVÃO, Andréia (Org.). Política e classes sociais no Brasil dos anos 2000. São Paulo: Alameda Editorial, 2012, p. 69-106.

CANITROT, A. El salario real y la restricción externa de la economía. Desarrollo Económico, Buenos Aires, v. 23, n. 91, p. 423-428, out./dez. 1983.

CARRERA, J. Renta agraria, ganancia del capital y tipo de câmbio: respuesta a Rolando Astarita. Buenos Aires: Centro para la Investigación como Crítica Práctica, 2009.

CURIA, E. El pendulo Argentino: hacia una recidiva? Pensando en Marcelo Diamand. [s.1.] Centro de Análisis Social y Económico, abr. 2008.

DAMILL, M.; FRENKEL, R. Las politicas macroeconômicas en la evolución reciente de la economía argentina. Buenos Aires: Cedes, 2009.

DAMILL, M.; FRENKEL, R.; MAURIZIO, R. Macroeconomic policy changes in Argentina at the turn of the century. Nuevos Documentos, Buenos Aires, Cedes, n. 29, 2007.

DAMILL, M.; FRENKEL, R.; MAURIZIO, R. Macroeconomic policy for full and productive employment and decent work for all: an analysis of the Argentine experience. Geneva: International Labour Office (ILO), Employment Sector, Employment Department, 2011.

DIAMAND, M. (1973). Doctrinas económicas, desarrollo e independência. Buenos Aires: Paidos, 2007.

DIAMAND, M. Overcoming Argentina's stop-and-go economic cycles. In: HARTLYN, J.; MORLEY, S. (Ed.). Latin American political economy: financial crisis and political change, Boulder, CO: Westview Press, 1986.

DONDA, V.; MERCHÁN, C. Errores, oportunismos y coherencias. Página 12, 19 Jul. 2008.

ESTEVE, M. Todas las voces, todas: ¿todas? Discurso hegemónico en el conflicto campo-gobierno por las retenciones móviles en 2008. In: GALAFASSI, G. et al. Ejercicios de hegemonía - Lecturas de la Argentina contemporánea a la luz del pensamiento de Antonio Gramsci. Compilado por G. Galafassi. 1. ed. Buenos Aires: Herramienta, 2011.

FIORITO, A.; GUAITA, N.; GUAITA, S. El mito del crecimiento económico dirigido por el tipo de cambio competitivo. Circus, Revista Argentina de Economia, n. 5, Mayo 2013. 
FRENKEL, R.; RAPETTI, M. Fragilidad externa o desindustrialización: ¿Cuál es la principal amenaza para América Latina en la próxima década?"Santiago: Cepla, División de Desarrollo Económico, nov. 2011.

KATZ, C. El agro-capitalismo de la soja. 2008. Disponível em: www.lahaine.org/katz. Acesso em: 21 jan. 2012.

KATZ, C. Los nuevos desequilibrios de la economía argentina. Anuario EDI, Buenos Aires, n. 5, sept. 2010.

MARX, K (1875). Crítica do Programa de Gotha. In: CRITICA do Programa de Gotha. São Paulo: Boi Tempo, 2012.

MECHON. Lineamentos estratégicos para el desarrollo productivo de la Argentina. Buenos Aires: Ministerio de Economía y Producción, República Argentina, 2007.

MEDEIROS, C. A. Rivalidade estatal, instituições e desenvolvimento econômico. In: FIOR, J. L.; MEDEIROS, C. A. Polarização mundial e crescimento. Rio de Janeiro: Vozes, 2001.

MEDEIROS, C. A. Financial dependency and growth cycles in Latin American countries. Journal of Post Keynesian Economics, v. 31, n. 179, 2008.

MEDEIROS, C. A. Auge e declínio dos Estados Desenvolvimentistas. Novos Desafios, Parcerias Estratégicas, v. 15, n. 30, 2010.

LERNER, A. P. Money as a creature of the State. American Economic Review, v. 37, n. 2, p. 312-317, 1947.

SERRANO, F. A economia americana, o padrão dólar flexível e a expansão mundial nos anos 2000. In: FIORI, J. L.; MEDEIROS, C.; SERRANO, F. O mito do colapso do poder americano. Rio de Janeiro: Record, 2008.

SERRANO, F. O conflito distributivo e a teoria da inflação inercial. Revista de Economia Contemporânea, Rio de Janeiro, v. 14, n. 2, p. 395-421, maio/ago. 2010.

WEISBROT, M.; RAY, R.; MONTECINO, J. A.; KOZAMEH, S. The Argentine success story and its implications. London: CEPR - Center For Economic and Policy Research, out. 2011. Disponível em: http://www.cepr.net/documents /publications/argentina-success-2011-10.pdf.

VERNENGO, M. Más acerca de la propaganda negativa de FT sobre la argentina. 2011. Disponível em: http://grupolujan-circus.blogspot.com.br/. 